\title{
Murine Models of Hepatitis A Virus Infection
}

\author{
Asuka Hirai-Yuki, ${ }^{1}$ Jason K. Whitmire, ${ }^{2,3}$ Michael Joyce, ${ }^{4,5}$ D. Lorne Tyrrell, ${ }^{4,5}$ \\ and Stanley M. Lemon ${ }^{3,6}$ \\ ${ }^{1}$ Division of Experimental Animal Research, National Institute of Infectious Diseases, Tokyo 208-0011, Japan \\ ${ }^{2}$ Department of Genetics, University of North Carolina, Chapel Hill, North Carolina 27599 \\ ${ }^{3}$ Department of Microbiology \& Immunology, University of North Carolina, Chapel Hill, North Carolina 27599 \\ ${ }^{4}$ Department of Medical Microbiology and Immunology, University of Alberta, Edmonton T6G 2E1, Canada \\ ${ }^{5}$ Li Ka Shing Institute for Virology, University of Alberta, Edmonton T6G 2E1, Canada \\ ${ }^{6}$ Lineberger Comprehensive Cancer Center, University of North Carolina, Chapel Hill, North Carolina 27517 \\ Correspondence: smlemon@med.unc.edu
}

\begin{abstract}
Mechanistic analyses of hepatitis A virus (HAV)-induced pathogenesis have long been thwarted by the lack of tractable small animal models that recapitulate disease observed in humans. Several approaches have shown success, including infection of chimeric mice with human liver cells. Other recent studies show that HAV can replicate to high titer in mice lacking expression of the type I interferon (IFN) receptor (IFN- $\alpha / \beta$ receptor) or mitochondrial antiviral signaling (MAVS) protein. Mice deficient in the IFN receptor show critical features of type A hepatitis in humans when challenged with human HAV, including histological evidence of liver damage, leukocyte infiltration, and the release of liver enzymes into blood. Acute pathogenesis is caused by MAVS-dependent signaling that leads to intrinsic apoptosis of hepatocytes.
\end{abstract}

$\bigvee_{\mathrm{p}}^{\mathrm{in}}$ ral hepatitis represents a serious global problem, yet relatively little is known about the molecular mechanisms of pathogenesis of hepatotropic viruses, and the contribution of host immune responses to virus control or liver damage. A major impediment to understanding the underlying mechanisms of pathogenesis has been the lack of a suitable small animal model that accurately recapitulates features of the infection in humans. There are five viruses associated with hepatitis in humans. Hepatitis A virus (HAV), hepatitis $B$ virus (HBV), hepatitis $\mathrm{C}$ virus (HCV), and hepatitis D virus (HDV) infections are able to infect only humans and non- human primates (Lanford et al. 2011; Winer et al. 2016). Hepatitis E virus (HEV) appears to have a broader natural host range and is the only zoonotic virus among these five, yet the development of a useful small animal model for hepatitis $\mathrm{E}$ also has been difficult (Doceul et al. 2016; see Li and Wakita 2018). There is a crucial need to develop improved models to dissect the molecular and cellular mechanisms determining host responses within the unique microenvironment of the liver (Altevogt et al. 2011; Protzer et al. 2012). Here, we summarize recent successful efforts to establish murine models of HAV infection.

Editors: Stanley M. Lemon and Christopher Walker

Additional Perspectives on Enteric Hepatitis Viruses available at www.perspectivesinmedicine.org

Copyright (C) 2019 Cold Spring Harbor Laboratory Press; all rights reserved; doi: 10.1101/cshperspect.a031674

Cite this article as Cold Spring Harb Perspect Med 2019;9:a031674 
A. Hirai-Yuki et al.

\section{MURINE MODELS OF VIRAL HEPATITIS}

Laboratory mice are the most commonly used animal model for understanding human diseases caused by virus infections. Mice are inbred, genetically defined, and their genome can be manipulated. Because specific genes can be ablated or mutated in mice, it is possible to assess the role of individual proteins in viral entry, replication, disease pathogenesis, and other complex aspects of host-virus interaction. However, hepatitis viruses are relatively species-specific and generally possess a very narrow host species range. Thus, establishing infection in the mouse liver has been a significant barrier to developing murine models of hepatitis. However, recent findings show that this fundamental hurdle can be overcome, and there are now mouse models that support infection with $\mathrm{HBV}, \mathrm{HCV}$, and recently $\mathrm{HAV}$.

$\mathrm{HBV}$ and $\mathrm{HCV}$ are unable to infect wildtype mice, as mice lack virus entry receptor(s) for these viruses on hepatocytes (Meuleman and Leroux-Roels 2008; Chayama et al. 2011). An early approach to circumvent this limitation was to generate transgenic mice that overexpress the full-length HBV genome in hepatocytes (Guidotti et al. 1995). In such mice, virus particles are produced and exported into the bloodstream but do not reenter hepatocytes in the mouse liver, which lacks HBV receptors. Consequently, the mice fail to generate HBV covalently closed circular DNA (cccDNA), which is the normal transcriptional template for production of new viral genomes in natural infection. The viral life cycle is thus incomplete in this model. Nonetheless, these mice have been instrumental in learning how immune cells infiltrate the liver and express cytokines that limit viral gene expression. An alternative approach is to use a recombinant adeno-associated virus (AAV) vector to bypass the lack of cellular receptors for the virus. Mice inoculated with AAV vectors encoding both the HBV and HDV genomes produce infectious HDV particles and develop liver damage (Suarez-Amaran et al. 2017). This model could be used to investigate cellular requirements for HBV and HDV production and subsequent inflammatory cell responses, but again lacks the ability for newly produced virions to infect the liver.

Similarly, there has been limited success in efforts to model HCV infection. An early approach involved use of immunodeficient mice with chimeric human/mouse livers. Alb-urokinase-type plasminogen activator (uPA) transgenic mice overproduce a uPA in the liver encoded by a tandem array of four murine uPA genes placed under the control of the albumin promoter (Heckel et al. 1990). These transgenic mice become hypofibrinogenemic, with progressive death of hepatocytes. This creates an environment that facilitates transplanted hepatocytes repopulating the liver (Sandgren et al. 1991; Brown et al. 2000). Crossing mice transgenic for Alb-uPA with severe combined immunodeficiency (SCID)/beige mice, and selecting for animals homozygous for all three traits, allowed for efficient engraftment of human hepatocytes into the mouse liver. These Alb-uPA/ SCID mice were the first nonprimate animals shown to support HCV infection in vivo (Mercer et al. 2001). They have been used widely to study HCV as well as HBV (Mercer et al. 2001; Meuleman and Leroux-Roels 2008; Douglas et al. 2010; Chayama et al. 2011), and are useful for investigating the bioavailability and efficacy of antivirals, cellular mechanisms of liver pathogenesis, and innate inflammatory processes (Mercer et al. 2001; Walters et al. 2006; Joyce et al. 2009; Foster et al. 2014). However, AlbuPA/SCID mice are severely immunocompromised because of the lack of $\mathrm{T}$ and $\mathrm{B}$ cells and cannot be used to study adaptive immune responses and their contribution to infection resolution or pathogenesis. Moreover, the underlying liver injury in these mice results in elevations of serum alanine aminotransferase (ALT) and can interfere with interpreting data related to virus-induced pathogenesis.

More recently, immunodeficient AFC8-hu HSC/Hep mice were developed with hepatocyte-specific expression of an inducible suicide gene. Following ablation of the endogenous hepatocytes, these animals can be engrafted with both human hematopoietic stem cells and hepatocyte progenitor cells, resulting in mice with both human immune cells and human hepato- 
cytes (Washburn et al. 2011; Bility et al. 2016). Once engrafted, these mice become permissive for HBV or HCV infection, and moreover develop a human immune system. They develop both liver inflammation and fibrosis when infected, and mount an HCV-specific T-cell response. These mice show substantial potential for analyzing multiple features of infection-related pathogenesis, testing new antiviral strategies, and possibly developing translatable human vaccines. However, technical variance related to engraftment efficiency and the high expense for generating each mouse pose significant challenges. Moreover, this model does not easily take advantage of the benefits of mouse genetics to explore at a molecular level of detail how virus-hepatocyte interactions contribute to pathogenesis.

Another approach is to "humanize" mice at a genetic level to make them susceptible to infection with hepatitis viruses. Thus, $\mathrm{HCV}$ can infect hepatocytes in transgenic mice engineered to express human CD81 and occludin (OCLN), two of the four human molecules that act as essential factors for entry of HCV into hepatocytes (Dorner et al. 2011, 2013). When innate antiviral responses are blunted in these receptor transgenic mice, $\mathrm{HCV}$ completes its entire life cycle and establishes viremia. However, replication is limited and a downside to this model is that the mice fail to show clinical features of HCV infection.

Yet another approach is represented by an exciting new model in which mice were infected with an HCV-related surrogate rat hepacivirus (Billerbeck et al. 2017). The rat hepacivirus-infected mice developed viremia and showed evidence of liver damage. A T-cell response to the virus in immune-competent mice led to clearance by 3 weeks of infection but with associated liver injury, likely caused by the responding $\mathrm{T}$ cells. Depleting $\mathrm{CD}^{+} \mathrm{T}$ cells before challenge resulted in a persistent infection and impaired $\mathrm{CD}^{+} \mathrm{T}$-cell responses. Overall, the rat hepacivirus infection model resembles the virological and immunological features of HCV infection in humans. Because standard laboratory mice can be used, the model can take advantage of numerous mutant lines of mice to gain deeper under- standing of how HCV-like viruses cause disease. The model can also be used to study the adaptive immune response to hepacivirus infection and will be important for vaccine development.

Much less effort has been devoted to developing similar murine models of HAV. In contrast to $\mathrm{HBV}$ and $\mathrm{HCV}$, cell culture-adapted HAV has been reported to replicate efficiently in a murine hepatocyte-derived cell line after adaptation through serial passaging (Feigelstock et al. 2005). In contrast, we have found that HM175 virus adapted to growth in African green monkey kidney cells (AGMK) and BSC-1 cells replicates well in AML12 cells, which are derived from hepatocytes of a transgenic mouse expressing human transforming growth factor (TGF)- $\alpha$, without adaption (Hirai-Yuki et al. 2016b). Very low levels of HAV have been found in the livers of guinea pigs and rats inoculated with human $\mathrm{HAV}$, indicating a broader host range (Hornei et al. 2001; Costafreda et al. 2012). Highly diversified HAV-related viruses can be found in bats, rodents, hedgehogs, and shrews, and there is phylogenetic evidence that suggests the viruses have shifted between host species across time (Drexler et al. 2015; see Sander et al. 2018). In aggregate, these findings support the notion that it should be possible to establish a mouse model for HAV infection.

Broadly speaking, two different approaches have been attempted to establish mouse models of HAV infection, both with substantial success. SCID/Alb-uPA mice with chimeric livers secondary to engraftment with human hepatocytes have been shown to be permissive for HAV infection, and produce high viral titers in the blood, liver, and feces (Mercer et al. 2001; Pang 2013). Although these mice lack competent adaptive immune systems, they can be used to evaluate host cell tropism and the spread of virus within the host, as well as mechanism(s) underlying the prophylactic efficacy of neutralizing anti-HAV antibodies. An alternative approach has been to challenge mice deficient in interferon (IFN) signaling. Ifnar ${ }^{-1-}$ mice lacking expression of the IFN- $\alpha / \beta$ receptor are permissive for HAV infection and recapitulate many aspects of HAV pathogenesis (Hirai-Yuki et al. 2016a). Using such mice, we have learned that 
A. Hirai-Yuki et al.

IFN signaling potently restricts HAV infection in vivo, and that mitochondrial antiviral-signaling protein (MAVS) signaling through IFN regulatory factor (IRF) 3 and IRF7 contributes to pathogenesis.

\section{HAV INFECTION IN Alb-uPA/SCID BEIGE MICE WITH CHIMERIC HUMAN LIVERS}

In studies performed at the University of Alberta, Alb-uPA/SCID beige mice transplanted with human hepatocytes were readily infected with the HM175 strain of HAV using a wild-type virus inoculum derived from fecal material of an experimentally infected chimpanzee. Animals could be infected with HAV by either intraperitoneal or intravenous inoculation. HAV RNA was detected in sera and feces by the first week postinoculation and peaked by week three at $10^{6}$ genome equivalents $(\mathrm{GE}) / \mathrm{mL}$ in blood and $10^{9}$ $\mathrm{GE} / \mathrm{g}$ feces. Viral RNA was readily detectable in the chimeric liver by fluorescent in situ hybridization (FISH) using an HM175-strain-specific Affymetrix ViewRNA probe (Fig. 1). Samples of sera, bile, and feces from the HAV-infected mice were subjected to isopycnic gradient ultracentrifugation in iodixanol (Fig. 2). Similar to virus found in sera from experimentally infected chimpanzees and naturally infected humans, the virus present in sera from infected AlbuPA/SCID mice banded at a density of $\sim 1.07$ $\mathrm{g} / \mathrm{cm}^{3}$ (Fig. 2), consistent with it being quasienveloped HAV ([eHAV], Feng et al. 2013). In contrast, the density of the virus in bile and feces was $1.26 \mathrm{~g} / \mathrm{cm}^{3}$, consistent with nonenveloped naked HAV. These data provide strong evidence that the detergent action of bile salts strip the quasi-envelope from the virion following its se-

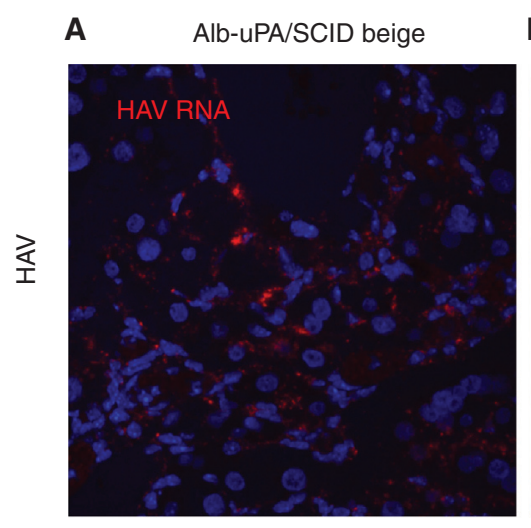

B Ifnart ${ }^{\%} /$ fngr ${ }^{\%}$

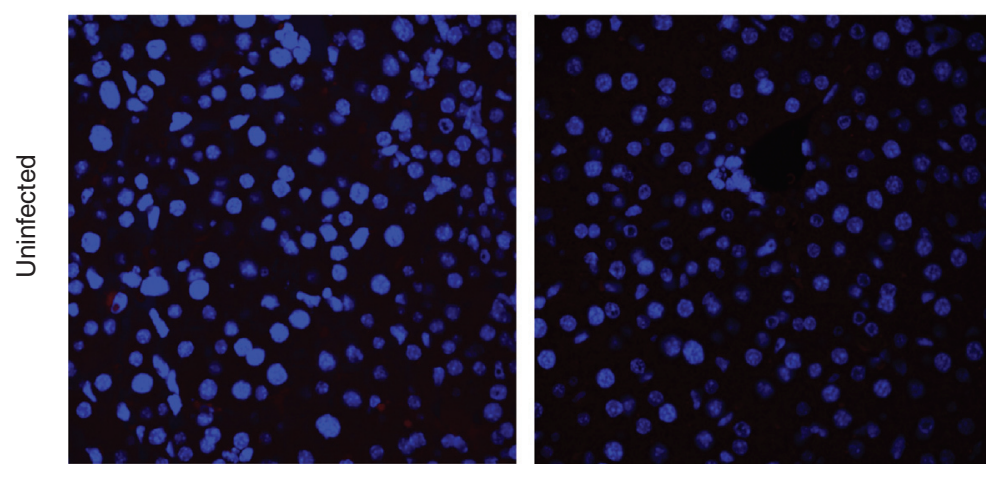

Figure 1. Fluorescent in situ hybridization (FISH) detection of intrahepatic hepatitis A virus (HAV) RNA in two different murine models supporting HAV infection. (A) Liver of an infected Alb-urokinase-type plasminogen activator ( $\mathrm{UPA}$ )/severe combined immunodeficiency (SCID) beige mouse containing $10^{8}$ genome equivalents (GE)/g liver tissue as determined by RT-qPCR. Red fluorescence indicates the presence of HAV RNA. (B) Similar image of a liver section from an infected Ifnar $1^{-/-}$Ifngrl $^{-1-}(\mathrm{DKO})$ mouse with $10^{7} \mathrm{HAV}$ GE/g liver tissue. 

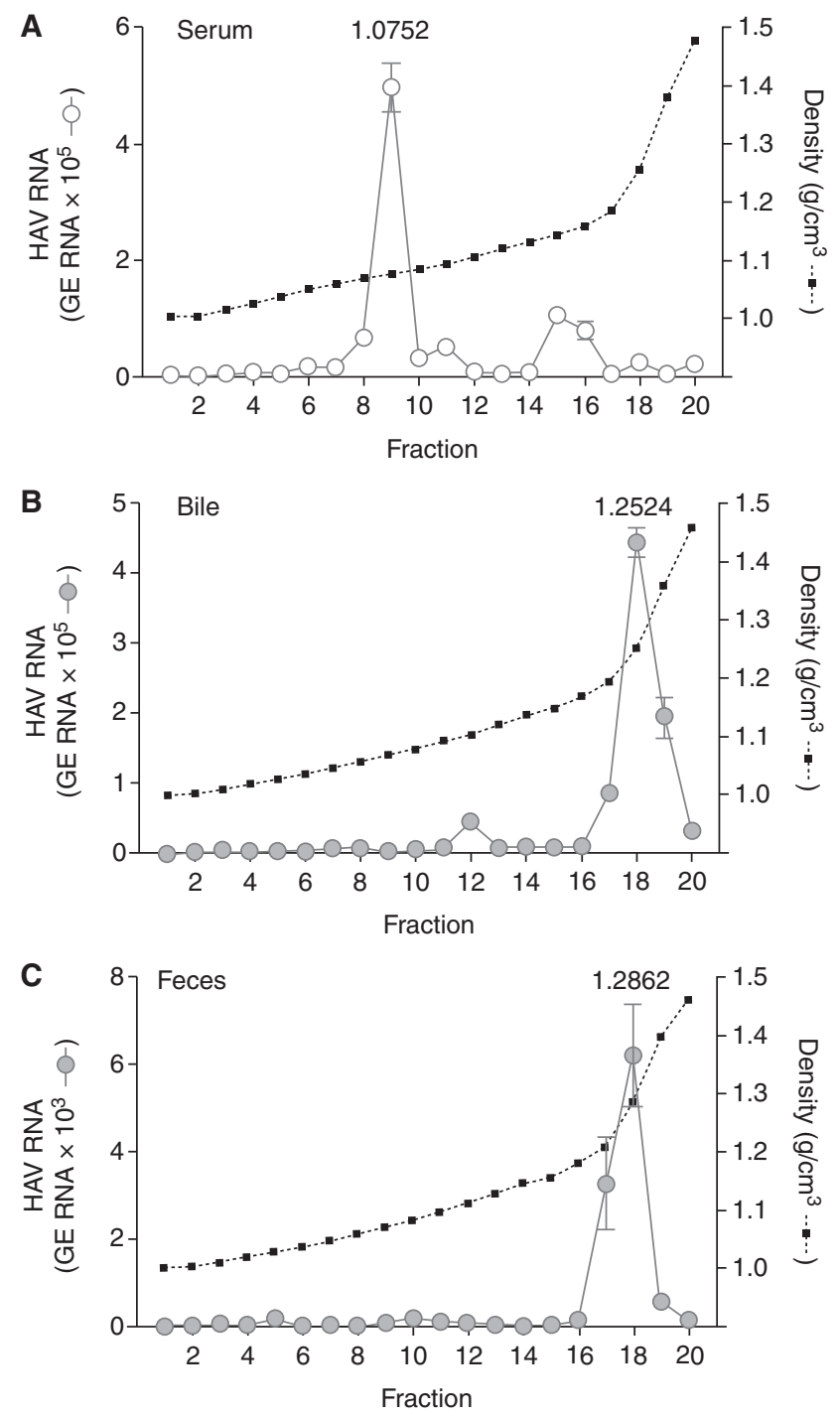

Figure 2. Buoyant densities of hepatitis A virus (HAV) virions in HAV-infected Alb-urokinase-type plasminogen activator (uPA)/SCID beige mice with chimeric human livers. Virus present in $(A)$ serum, $(B)$ bile, and $(C)$ feces of an infected Alb-uPA/SCID mouse were centrifuged to equilibrium in an isopycnic gradient as described by Feng et al. (2013). Twenty samples were collected from the top of the gradient tube and density determined using a refractometer. HAV RNA was assayed in all fractions by RT-qPCR. Only low-density virus $\left(1.06-1.10 \mathrm{~g} / \mathrm{cm}^{3}\right)$ consistent with quasi-enveloped HAV (Feng et al. 2013) was identified in the serum of infected mice, whereas only nonenveloped virus particles were found in mouse bile and feces.

cretion into the biliary system across the apical membrane of hepatocytes (Hirai-Yuki et al. 2016b). Both the eHAV and nonenveloped HAV recovered from infected Alb-uPA/SCID mice were infectious when used to passage the virus in naïve animals. In these immunodefi- cient mice, within which the uPA transgene results in progressive death of murine hepatocytes, there was no definitive evidence of hepatocyte damage related to HAV infection, and viral titers remained high in the sera until the animals were sacrificed 10 weeks postinoculation (Pang 2013). 
A. Hirai-Yuki et al.

Immunohistological studies revealed that HAV antigen was restricted to human hepatocytes staining for human cytokeratin 18 in the chimeric liver. HAV antigen was not detected in murine hepatocytes or other tissues from the Alb-uPA/SCID beige mice, including tissue from the gastrointestinal tract. The innate immune response to the virus in mice with chimeric human livers was examined at 4 and 7 weeks postinfection. Both human type I IFN (IFN- $\alpha 1$ and IFN- $\beta 1$ ) and type II IFN (IFN- $\gamma$ ) transcripts were significantly up-regulated in $\mathrm{HAV}$-infected chimeric mice compared with uninfected controls. However, human transcripts for type III IFNs (IL28 and IL29) and five IFN-stimulated genes (ISGs), IFIT2, IRF3, STAT1, IFI27, and MXI were down-regulated with HAV infection. These results are suggestive of an overall dampening of the innate immune response in the human hepatocytes, consistent with the minimal IFN responses observed in HAV-infected chimpanzees (Lanford et al. 2011).

Studies of HAV in cell culture have shown the virus is sensitive to type I IFNs in vitro (Vallbracht et al. 1984, 1985). Similarly, pegylated IFN- $\alpha 2$ a treatment of HAV-infected Alb-uPA/ SCID mice with chimeric human livers resulted in a slow diminution of HAV RNA in sera and feces, with the animals appearing to be cured after 8 weeks of treatment (Pang 2013).

One unexpected observation in these studies of HAV infection in mice was that Alb-uPA/ SCID mice with chimeric human livers became infected following exposure of the animals to $\mathrm{HAV}$-infected bedding. This was unexpected in the absence of parenteral exposure to the virus, because the only human cells present in these animals were in the liver. Further studies showed that the virus was not transmissible by oral gavage, but was transmissible by intranasal exposure (Pang 2013). The physiologic significance of this finding is uncertain, but bears further investigation.

HAV infection in Alb-uPA/SCID beige mice transplanted with human hepatocytes is a valuable animal model for the study of HAV pathogenesis. It recapitulates basic host/pathogen interactions and mimics the disease process observed in both patients and chimpanzee models in terms of the biogenesis of quasi-enveloped virus. Its major disadvantages are the lack of adaptive immunity and the presence of ongoing hepatotoxicity related to transgene expression, but the model provides unique opportunities to study the trafficking of HAV in vivo as well as mechanisms underlying protection afforded by adoptive transfer of neutralizing anti-HAV antibodies.

\section{TYPE I IFN-DEPENDENT HOST RANGE OF HAV: THE Ifnar1 ${ }^{-/-}$MOUSE MODEL}

Type I IFN is a major mediator of antiviral defense, and viruses have evolved numerous mechanisms to avoid inducing IFN or to prevent IFNinduced signaling (Garcia-Sastre and Biron 2006). Engagement of the type I IFN receptor results in the expression of numerous IFN-stimulated genes that include cytosolic RNases that can degrade viral RNA and other factors that interfere with translation of the viral genome, reducing viral gene expression and replication. HAV replication is strongly suppressed by IFN (Yang et al. 2007; Qu et al. 2011). However, HAV infection results in the expression of stable viral $3 \mathrm{C}^{\text {pro }}$ protease precursors ( $3 \mathrm{ABC}$ and $3 \mathrm{CD}$ ) that degrade human MAVS and TIR-domain-containing adapter-inducing IFN- $\beta$ (TRIF), respectively, intracellular signal adaptor proteins required for the induction of IFNs. Proteolytic cleavage of MAVS and TRIF, as well as the nuclear factor (NF)- $\kappa \mathrm{B}(\mathrm{NF}-\kappa \mathrm{B})$ essential modulator (NEMO) (Wang et al. 2014), blunts the IFN response in infected human hepatocytes (see Feng and Lemon 2018). However, the amino acid sequence targeted by the HAV $3 \mathrm{ABC}$ protease in human MAVS is not conserved in the murine MAVS ortholog, and HAV 3ABC cannot degrade murine MAVS (Hirai-Yuki et al. 2016a). In line with this, HAV cannot disrupt the rapid induction of IFN responses in murine hepatocytes, and wild-type mice are resistant to HAV infection (Hirai-Yuki et al. 2016a).

In contrast, Ifnar $1^{-1-}$ mice that lack expression of the type I IFN receptor and are thus deficient in IFN signaling are permissive for HAV infection (Hirai-Yuki et al. 2016a). Infection in Ifnarl $^{-/-}$mice is characterized by fecal 
shedding of infectious HAV, low-grade viremia, and liver damage reflected in elevated serum ALT activity (Fig. 3A,C). Abundant viral RNA is evident within hepatocytes of infected Ifnar $1^{-1-}$ mice (Fig. 3B), although both RTqPCR and FISH show there is less than in the chimeric human livers of Alb-uPA/SCID beige mice infected with a very similar viral inoculum (Fig. 1). Whether this reflects the species of origin of the infected hepatocyte (mouse versus human), or the immunosuppression of AlbuPA/SCID mice is not clear. We estimate the minimal infectious dose of virus in these animals by the intravenous route to be between 50 and 500 infectious virus particles, assuming a conservative particle/infectivity ratio of $150 / 1$ for HAV (Fig. 4).

HAV replication in Ifnar $^{-/-}$mice appears to be restricted to hepatocytes, despite the fact that all nucleated cells lack the IFN receptor. Tenfold less-viral RNA is found in the spleen and lung, and none in tissues of the small and large intestine. Infected livers show multifocal inflammatory cell infiltrates, often surrounding necrotic or apoptotic hepatocytes (Fig. 5) (see Cullen 2018). Infected mice produce both nonenveloped and quasi-enveloped virions, which are found in the feces and blood of infected chimpanzees and humans, respectively, as described above (Feng et al. 2013). Virus present in the bile of these animals banded at a range of densities in isopycnic gradients, suggesting the presence of virions undergoing quasi-envelope removal by bile salts (Hirai-Yuki et al. 2016b). Thus, infection in Ifnar $1^{-/-}$mice closely resembles acute HAV infection in humans and represents the most genetically tractable mouse model to have been developed for any of the five human hepatitis viruses. Compared with relatively brief periods of virus shedding during HAV infection in chimpanzees and other nonhuman primates (Li and Wakita 2018); however, fecal shedding of the virus persists along with ALT elevations for many weeks in Ifnar $1^{-/-}$ mice, and the infection appears to be brought under control substantially more slowly (Fig. 3) (Lanford et al. 2011; Hirai-Yuki et al. 2016a).

These data show that the capacity of HAV to evade IFN responses to a large extent defines its host species range. More typically, the host range of viruses is limited by species-specific expression of essential host factors, particularly receptor(s) required for virus entry into cells. This has been shown for various viruses, including HCV (Dorner et al. 2011) and poliovirus, which is classified in the same virus family ( $P i-$ cornaviridae) as HAV (Ren et al. 1990). RNA viruses in particular can accumulate adaptive mutations during serial passage in a new host species, resulting in enhanced replication capacity. Such adaptive mutations often occur in genes encoding viral surface proteins that enable interaction with cellular receptors and enhance viral entry, as exemplified by severe acute respiratory syndrome (SARS) coronavirus and influenza viruses (Li 2013; Sang et al. 2015). The wild-type HAV isolate used to infect Ifnar $1^{-1-}$ mice originated from a chimpanzee infected with the HM175 strain of HAV, which was isolated from an infected human in Australia (Gust et al. 1985; Cohen et al. 1987). Despite five serial passages of HAV in mice, we found only a single nonsynonymous nucleotide substitution in the polyprotein-coding region of the genome. This mutation is close to the carboxyl terminus of the $3 \mathrm{D}^{\text {pol }}$ polymerase and results in a conservative Arg to Lys substitution at 3D-468 (Hirai-Yuki et al. 2016a). It does not appear to have much impact on the ability of the virus to replicate in Ifnar $1^{-/-}$mice. Thus, wild-type mice express endogenous molecules that can be used by HAV as entry receptors, and the principal factor limiting the host species range of HAV is IFN signaling.

An interesting feature of HAV infection in Ifnar $1^{-/-}$mice is that the HAV RNA copy number remains high in the mouse liver, even after the virus has been cleared from the serum and is no longer detectable in feces and anti-HAV has developed (Fig. 3B) (Hirai-Yuki et al. 2016a). Such persistent intrahepatic viral RNA also has been observed in HAV-infected chimpanzees (Lanford et al. 2011; Zhou et al. 2012). Although HAV causes only acute infection in humans, symptomatic relapse with recrudescent fecal shedding of virus is common during recovery, and occurs in up to $20 \%$ of patients after ALT normalization and viral clearance (Sjogren et al. 1987; Glikson et al. 1992). The mechanism(s) 
A. Hirai-Yuki et al.
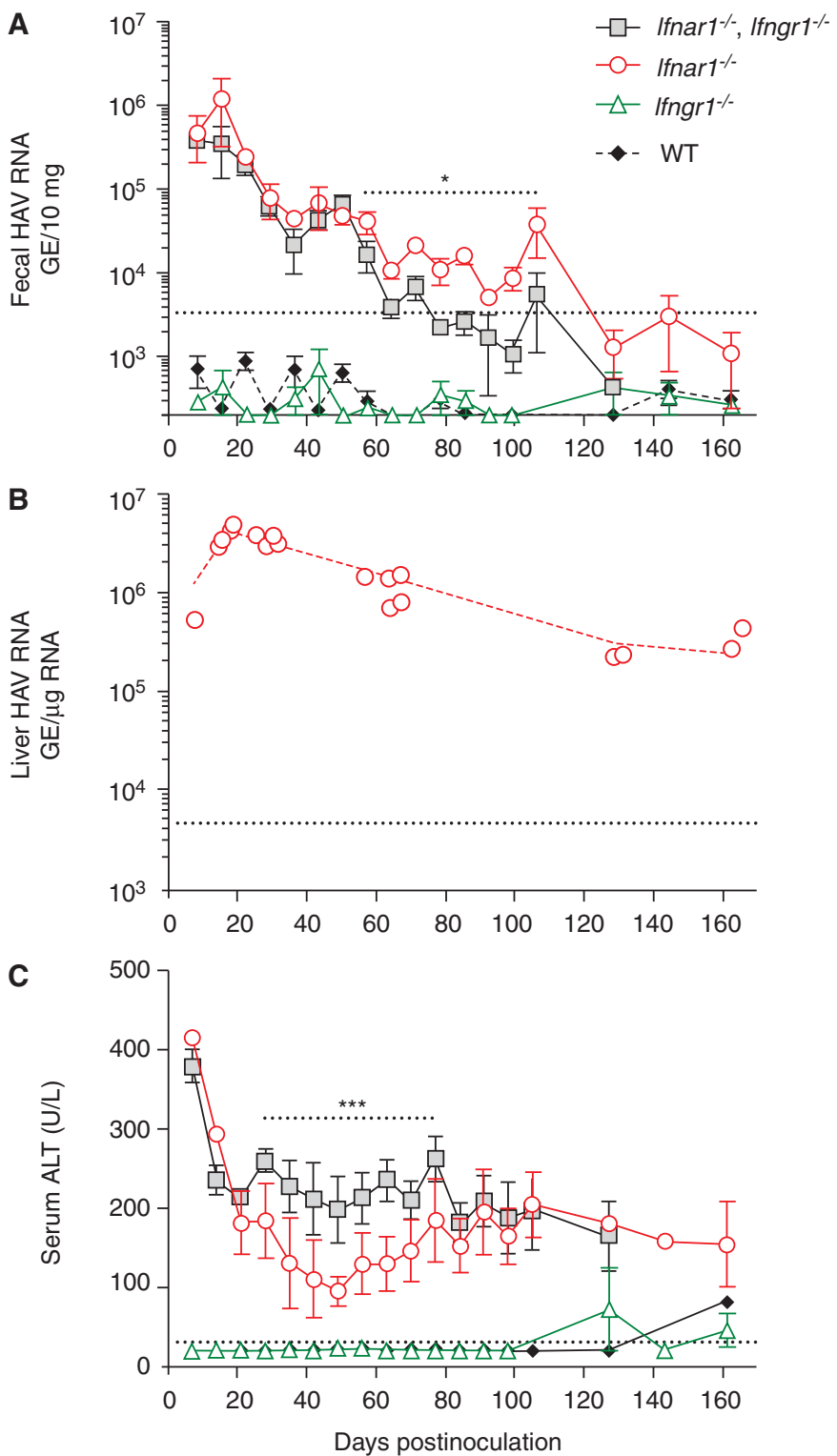

Figure 3. Hepatitis A virus (HAV) challenge of Ifnarl ${ }^{-1-}$, Ifngr $1^{-1-}$, and Ifnarl $1^{-1-} /$ Ifngr $1^{-1-}$ double knockout (DKO) and wild-type (WT) B6 mice. WT mice or mice deficient in the type I interferon (IFN) receptor (Ifnar ${ }^{-/-}$), type II IFN receptor (Ifngr $1^{-1-}$ ), or both receptors (DKO) were inoculated intravenous (i.v.) with $10^{8}$ genome equivalents (GE) of 4th mouse passage HAV. RT-qPCR quantitation of HAV RNA in $(A)$ fecal samples, $(B)$ liver, and $(C)$ serum alanine aminotransferase (ALT) activity were assessed at multiple time points. WT and Ifngr $1^{-1-}$ mice showed no evidence of infection or increased ALT at any time. In contrast, both Ifnar $1^{-1-}$ and DKO mice shed virus in feces for 2 months. Ifnar $1^{-1-}$ mice showed greater fecal shedding for a lengthier period compared with DKO mice. Viral RNA in the liver peaked during the first month of infection, declined by 2 months and was maintained at $\sim 3 \times 10^{5} \mathrm{GE} / \mu \mathrm{g}$ for 5 months. ALT levels in both Ifnar $1^{-1-}$ and DKO mice peaked during the first 2 weeks of infection, then rapidly declined to a homeostatic level that was maintained for 5 months. Increases in serum ALT activity correlated with persistence of viral RNA in the liver. There was a transient period when DKO mice showed significantly greater ALT activity than Ifnar $1^{-1-}$ mice, suggesting a possible role for IFN- $\gamma$ in liver pathogenesis. (Modified from data in Hirai-Yuki et al. 2016a.) 


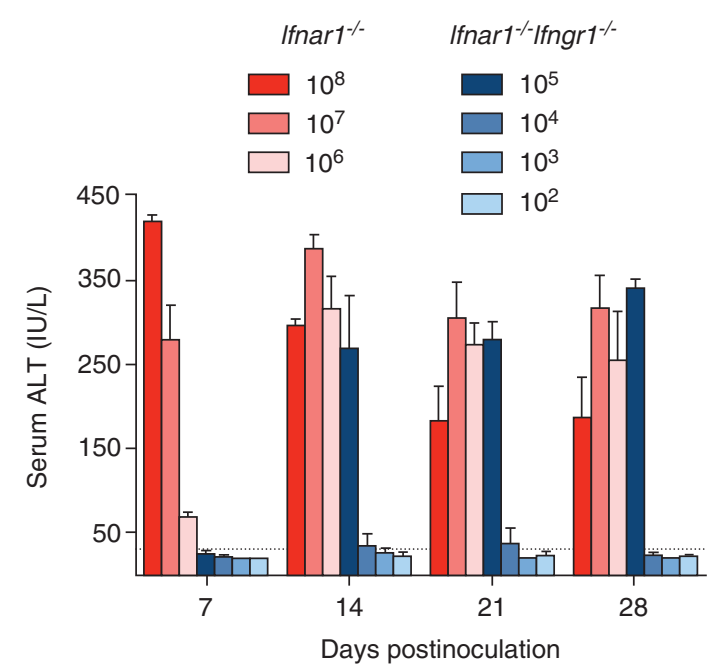

Figure 4. Hepatitis A virus (HAV) inoculum size and infection kinetic in Ifnar1 ${ }^{-1-}$ and Ifnarl ${ }^{-/-}$Ifngr1 $1^{-1-}$ (DKO) mice. Ifnarl $1^{-/-}$and Ifnarl ${ }^{-/-}$Ifngr $^{-/-}$mice were inoculated intravenously with 4th mouse passage virus ranging from $10^{8}$ to $10^{2}$ genome equivalents (GE) as shown at the top. Lack of the type I interferon (IFN) receptor determines permissiveness and these two knockouts appear similar in terms of susceptibility to infection. Higher titer inocula result in earlier increases in serum alanine aminotransferase (ALT). The minimal infectious dose is between $10^{4}$ and $10^{5} \mathrm{GE}$, which is equivalent to 50-500 infectious virus particles given the particle/infectivity ratio of HAV.

responsible for this is unknown. Similarly, the nature of the viral RNA persisting in the liver of infected chimpanzees and Ifnar $1^{-1-}$ mice is uncertain. It could reflect continued low-level viral replication, or possibly neutralized virus that has been stabilized within an endosomal compartment by antibodies. Its presence raises a number of interesting questions, such as the cell type within which it resides, whether it reflects a source of residual virus that might contribute to disease relapse, whether it is completely dormant or replicating at low levels, and how it avoids clearance by the immune system?

\section{MAVS-DEPENDENT PATHOGENESIS OF HEPATITIS A}

During infection, HAV RNA is present within the cytosol where it can be sensed by the RNA helicases retinoic acid-inducible gene-I (RIG-I) and melanoma differentiation-associated gene 5 (MDA5), or by Toll-like receptor 3 (TLR3) after being taken up into endosomes. RIG-I and MDA5 induce signals converging at MAVS, ultimately stimulating IFN responses (see Feng and Lemon 2018). HAV RNA detected by TLR3 signals via TRIF and also induces IFNs. Because IFNs limit HAV replication and HAV has evolved to express proteases that cleave human MAVS and TRIF, we investigated whether HAV could replicate in MAVS-deficient $\left(\right.$ Mavs $\left.^{-1-}\right)$ or TRIF-deficient $\left(\right.$ Trif $\left.^{-1-}\right)$ mice. We found that MAVS-deficiency alone permitted replication, whereas TRIF-deficient mice resisted infection as well as wild-type mice (HiraiYuki et al. 2016a). This indicates that MAVS and its downstream signaling pathway is a central regulator of HAV replication. Consistent with this notion, livers from HAV-infected MAVSdeficient mice showed minimal induction of IFNs or ISG transcripts. The virus was more completely hepatotropic in $\mathrm{Mavs}^{-/-}$mice, reaching $10^{7.5} \mathrm{GE} / \mu \mathrm{g}$ total RNA in the liver, approximately 1000 -fold the amount present in spleen (Hirai-Yuki et al. 2016a).

In striking contrast to infected Ifnar $1^{-/-}$ mice, infected MAVS-deficient mice showed no hepatic disease-there was no increase in serum ALT, very limited influx of leukocytes, and minimal hepatic inflammation and apopto- 
A. Hirai-Yuki et al.

Ifnar1 ${ }^{-} 3.52 \times 10^{6} \mathrm{GE} / \mu \mathrm{g}$ RNA

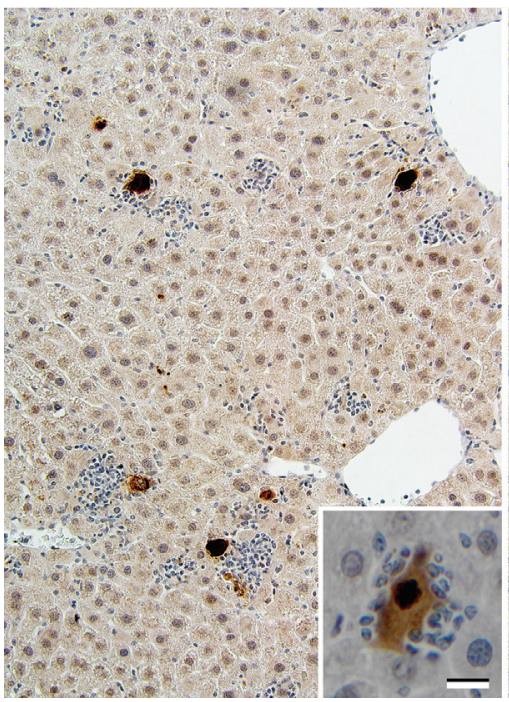

Mavs $^{-/ 2} 2.75 \times 10^{7} \mathrm{GE} / \mu \mathrm{g}$ RNA

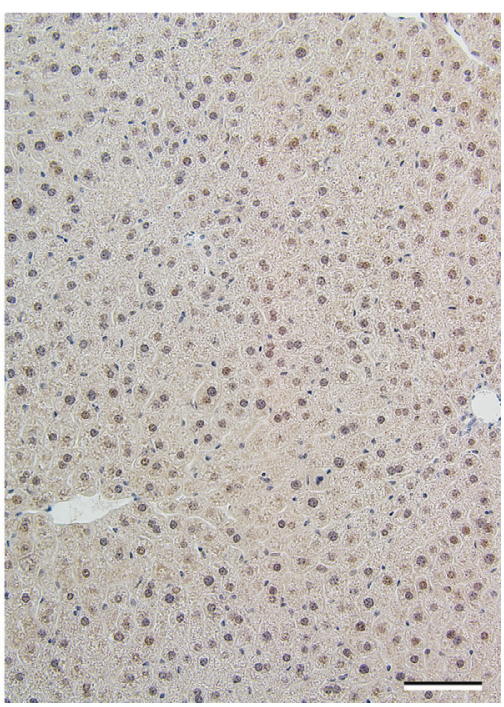

Figure 5. Mitochondrial antiviral-signaling protein (MAVS)-associated apoptosis in hepatitis A virus (HAV)infected mice. Immunohistochemical staining for cleaved caspase-3 was performed on liver sections from Ifnarl ${ }^{-/-}$and $\mathrm{Mavs}^{-/-}$mice 15 days after infection. Ifnarl ${ }^{-/-}$liver (left) shows evidence of caspase activation (brown stain), magnified in the inset. Cells with caspase-3 staining also show surrounding inflammatory cell infiltrates. Neither cleaved caspase- 3 nor cellular infiltrates are present in the Mavs $^{-1-}$ livers, despite an almost 10-fold higher abundance of viral RNA. Scale bars, $12.5 \mu \mathrm{m}$ (left, inset); $100 \mu \mathrm{m}$ (right). (From Hirai-Yuki et al. 2016a; reprinted, with permission, from The American Association for the Advancement of Science ( 2016.$)$

tic hepatocytes in infected $\mathrm{Mavs}^{-1-}$ mice (Figs. 5 and 6). This is remarkable given that that there was 10 times more virus in the livers of infected $\mathrm{Mavs}^{-1-}$ mice compared with the Ifnarl ${ }^{-1-}$ mice. On closer inspection, we inferred that hepatocyte death in HAV-infected Ifnar ${ }^{-1-}$ mice was unlikely to be driven by perforin or death receptor-mediated signaling induced by infiltrating immune cells (Fig. 7), because depletion of $\mathrm{CD}^{+}{ }^{+} \mathrm{T}$ cells, $\mathrm{CD} 8^{+} \mathrm{T}$ cells, or natural killer (NK) cells did not reduce the acute liver injury (Hirai-Yuki et al. 2016a). These results suggest that in Ifnar $1^{-/-}$mice, the activation of MAVS initiates apoptosis within infected hepatocytes. This apoptotic process does not occur in infected $\mathrm{Mavs}^{-1-}$ mice. Tenfold higher titers of virus were reached in the livers of $\mathrm{Mavs}^{-1-}$ mice compared with Ifnar $1^{-/-}$mice, likely caused by improved hepatocyte survival and continued virus production in the absence of MAVS signaling. Perhaps related to this, fecal shedding of virus continued unabated for months in the $\mathrm{Mavs}^{-1-}$ mice, in contrast to Ifnarl ${ }^{-/-}$mice in which it was brought under slow control (Figs. 3A and $6 \mathrm{~B})$.

MAVS signaling leads to the activation of IRF3 and IRF7, semiredundant transcription factors that drive expression of IFN as well as a select set of ISGs (Grandvaux et al. 2002). When challenged intravenously with $\mathrm{HAV}, \operatorname{Irf} 3^{-/-}$mice, $I r f 7^{-1-}$ mice and dually deficient $\operatorname{Irf3^{-1}} I r f 7^{-/-}$ mice became productively infected, yet showed minimal to no evidence of liver injury or hepatocellular apoptosis (Hirai-Yuki et al. 2016a). These results suggest that MAVS-mediated activation of IRF3/7 is responsible for apoptosis of infected hepatocytes. It may be that activated IRF3/7 induce hepatocyte apoptosis by directly driving the transcription of proapoptotic ISGs in an IFN-independent manner (Grandvaux et al. 2002). Possible candidates for this include IFIT2 (IFN-induced protein with tetratricopeptide repeats-2) (Reich 2013) or PMAIP1 (phorbol-12-myristate-13-acetate-induced protein-1) 

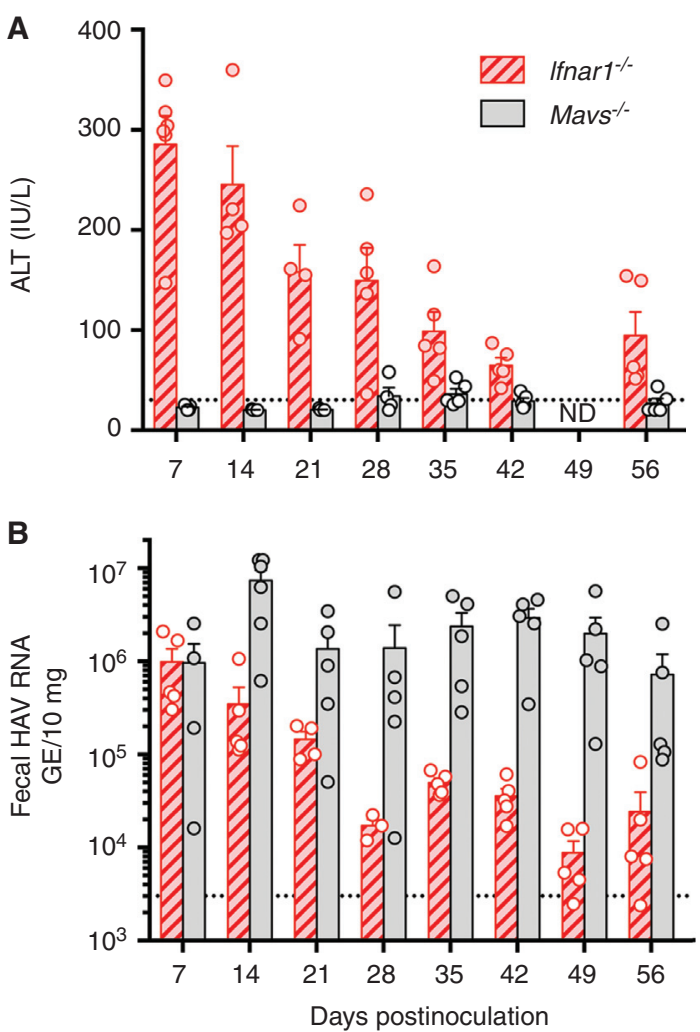

Figure 6. Absence of mitochondrial antiviral-signaling protein (MAVS)-signaling results in sustained fecal shedding of hepatitis A virus (HAV). (A) Serum alanine aminotransferase (ALT) activity, and (B) fecal viral shedding were tracked over time in infected Ifnarl $1^{-1-}$ and $\mathrm{Mavs}^{-1-}$ mice. Infected Ifnar ${ }^{-1-}$ mice show elevated ALT during the first 2 weeks followed by a gradual decline matched by reductions in fecal virus shedding. Mavs ${ }^{-1-}$ mice showed no evidence of increased ALT following infection, consistent with the absence of apoptosis and leukocyte infiltration of the liver, and sustained fecal shedding of virus. (From Hirai-Yuki et al. 2016a; reprinted, with permission, from The American Association for the Advancement of Science @ 2016.$)$

(Besch et al. 2009). Indeed, both Ifit2 and Pmaip1 transcripts were increased in infected Ifnarl $^{-/-}$mice, but minimal or absent in $\mathrm{Mavs}^{-1-}$ mice (Hirai-Yuki et al. 2016a). Alternatively, it may be that IRF3 directly interacts with mitochondrial Bax to increase its proapoptotic activity (Chattopadhyay et al. 2016).

Although the detailed mechanisms downstream from MAVS-IRF3/7 signaling in HAVinduced hepatocellular apoptosis are still to be determined, the HAV murine model has revealed three important functions of MAVS and subsequent IRF3/7 activity in the setting of acute HAV infection (Fig. 8). (1) MAVS-IRF3/7 induces the expression of IFN, leading to subsequent IFN receptor-STAT1/2-mediated signal- ing and expression of ISGs that restrict HAV replication. HAV must disable this process to successfully replicate in hepatocytes. (2) MAVS activation of IRF3 promotes intrinsic apoptosis of infected hepatocytes, which likely contributes to acute liver injury during infection. Interestingly, IRF3 activation, mediated by STING signaling, has also been linked to acute ethanolrelated liver injury (Petrasek et al. 2013). (3) MAVS-IRF3 signaling triggers inflammatory responses in the liver, which may further exacerbate liver injury. The recruitment of infiltrating cells (discussed below) is largely independent of $\mathrm{NF}-\mathrm{\kappa B}$ activity (as NF- $\mathrm{\kappa B}$ signaling is not ablated in $I r f 3^{-/-} \operatorname{Irf7}^{-/-}$mice), but is associated with MAVS-mediated increases in the chemokines 
A. Hirai-Yuki et al.

A

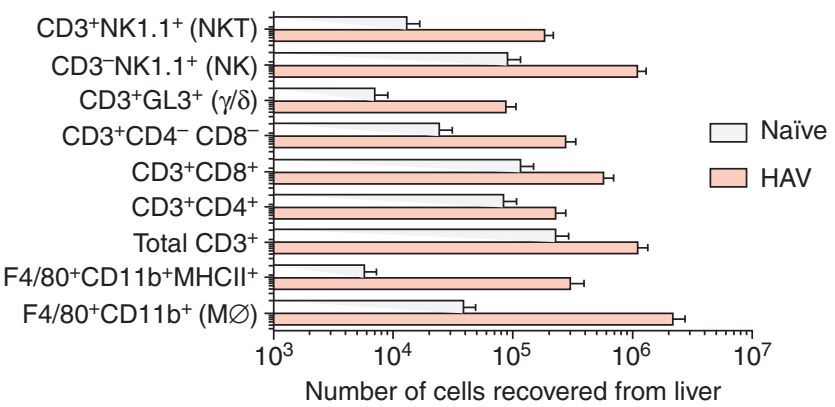

B

CD3

CD4

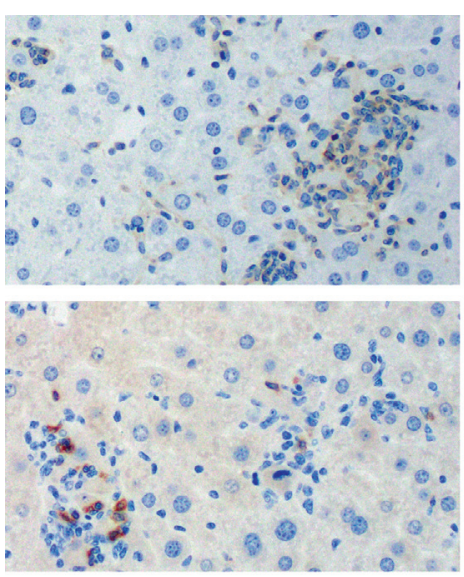

CD8

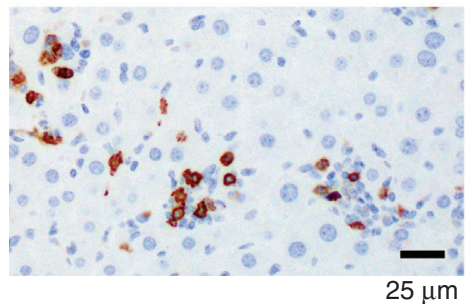

C

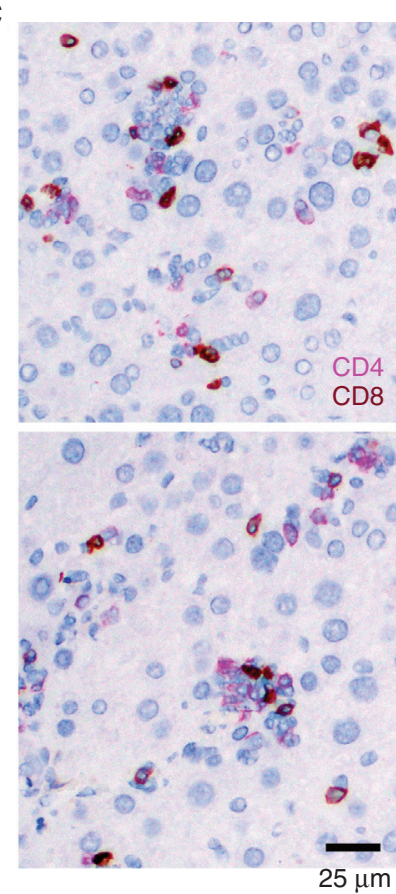

Figure 7. A myeloid-derived suppressor cell-like population is recruited to the liver during hepatitis A virus (HAV) infection. Leukocytes were identified in the livers of uninfected or HAV-infected Ifnar1 $1^{-1-}$ mice. (A) At day 7 postinfection, flow cytometry identified a robust increase in probable MDSC cells $\left(\mathrm{F} 4 / 80^{+} \mathrm{CD} 11 \mathrm{~b}^{+} \mathrm{MHCII}^{-}\right)$in the liver. Macrophage-like cells also showed an increase as a result of infection but were lower in number compared with other subsets of cells. There were also modest increases in $\mathrm{T}$ cells and a 10 -fold increase in $\mathrm{NK}^{+}$cells and $\mathrm{NK}^{+} \mathrm{T}$ cells. The change in the small population of $\gamma / \delta \mathrm{T}$ cells did not reach significance. $(B)$ Immunohistochemical staining of CD3, CD4, and CD8 in an Ifnar ${ }^{-1-}$ mouse 15 days postinfection, ALT $=528 \mathrm{IU} / \mathrm{L} .(C)$ Dual immunohistochemical staining of infected Ifnar $1^{-1-}$ liver at day 14 postinfection. The magenta represents anti-CD4 staining and the brown represents anti-CD8 staining. The image reveals a mixed cellular infiltrate, with a large proportion of the infiltrating cells staining for neither CD8 nor CD4.

CCL5 (RANTES), CCL2 (MCP1), CCL3 (MIP1a), and CXCL10 (IP-10) (Hirai-Yuki et al. 2016a) that likely recruit $\mathrm{T}$ cells, NK cells, and myeloid cell populations to the liver. These studies are the first to implicate a specific innate immune signaling pathway in virus-induced liver injury.

\section{HAV AND EHAV RECEPTOR USAGE IN MICE}

Because C57BL/6 mice can be infected by HAV when IFN signaling is ablated, they express the receptor molecule(s) required for the entry of 
the virus into hepatocytes. TIM1 (T-cell immunoglobulin and mucin-containing domain protein-1, which is otherwise known as hepatitis A cellular receptor-1 [HAVCR1]) has been widely accepted to be the receptor for HAV in humans for almost two decades (Feigelstock et al. 1998; McIntire et al. 2003; Manangeeswaran et al. 2012). However, although mice express a TIM1 ortholog, it is not essential for entry into murine hepatocytes as Tim1 $1^{-1-}$ Ifnar ${ }^{-1-}$ double knockout mice are readily infected with either HAV or eHAV (Das et al. 2017). TIM1 is a phosphotidylserine receptor, and it facilitates cellular entry and infection with numerous conventional enveloped viruses by binding phosphatidylserine on their surface (Moller-Tank and Maury 2014). It appears to act similarly with eHAV, as infection of mice with eHAV (but not naked HAV) is slightly delayed in Tim $1^{-1-}$ Ifnar $^{-1-}$ versus with Ifnar $1^{-1-}$ mice, as well as human hepatocytes in which TIM1 expression has been ablated by CRISPR/Cas9 gene editing (Das et al. 2017). Consistent with this, other studies indicate that phosphatidylserine residues are displayed on the surface of eHAV (Feng et al. 2015). The cellular receptor for HAV thus awaits detection. Mice are likely to be useful in confirming the identity of a candidate receptor in the future.

\section{IMMUNE RESPONSES TO HAV}

Observations made in the Ifnar $1^{-1-}$ mouse model of hepatitis A suggest that HAV infection may result in two distinct phases of pathogenesis. In Ifnar $1^{-1-}$ mice, there is an early acute stage when ALT levels greatly increase (e.g., $>200 \mathrm{IU} / \mathrm{L}$ serum in mice; Fig. 3C) and tissue sections show clear evidence of liver damage. This stage, which in Ifnarl ${ }^{-/-}$mice is mainly the result of intrinsic hepatocyte apoptosis caused by MAVS/-IRF3/7 signaling, lasts 2 weeks in mice but subsides afterward to a level that is sustained across time. The protracted period of continued low-level ALT release is proportional to virus load in the liver and corresponds to the period when adaptive immune responses emerge. Thus, virus-specific immune cell populations may contribute to ongoing liver pathogenesis beyond the acute stage. Whether two distinct stages of HAV pathogenesis exist in infected primates (humans and chimpanzees) is uncertain, but it seems likely both pathogenetic mechanisms are operative, albeit perhaps compressed in time and overlapping. Active infection (with appreciable shedding of virus in feces) is prolonged in Ifnar $1^{-1-}$ mice compared with chimpanzees (see Lanford et al. 2018), as is the continued elevation of ALT beyond the first few weeks of infection. It is possible that this results from a less robust adaptive immune response in Ifnar $1^{-1-}$ mice caused by a lack of innate immunity and a failure to properly "shape" the adaptive immune response.

\section{Antibody Responses}

HAV-specific antibody can be detected at 2 weeks postinfection in Ifnarl ${ }^{-1-}$ mice but does not peak until 35 days postinfection (Hirai-Yuki et al. 2016a), similar to what is seen in HAVinfected chimpanzees (Lanford et al. 2011), and in infected patients who show antibody after 3 weeks of infection (Lemon 1985). Neutralizing antibodies target the capsid; there are no viral proteins expressed on the surface of the quasienveloped eHAV virion (McKnight et al. 2017). Although the mechanism responsible for HAV neutralization is not known, antibody bound to the naked capsid could interfere with its attachment to a receptor and entry into cells, destabilize the capsid structure, or possibly lock the capsid conformation such that uncoating of the genome is prevented. The eHAV quasi-envelope prevents antibody binding to the capsid (Feng et al. 2013). Thus, with eHAV, neutralizing antibodies must act within late endosomal vesicles where they can bind the capsid after degradation of the quasi-envelope (Feng et al. 2013). HAV-infected Ifnarl ${ }^{-1-}$ and $\mathrm{Mavs}^{-1-}$ mice both develop HAV-specific IgG, but the antibody response is quicker in infected Ifnar $1^{-1-}$ mice, perhaps caused by a greater release of viral proteins from apoptotic or necrotic hepatocytes. Currently, we do not know the impact of anti-HAV antibody on the infection in mice, although it is plausible that as antibody 
A. Hirai-Yuki et al.

titer increases, sufficient intracellular neutralization may occur to limit the spread of eHAV in vivo. This may contribute to the diminution of viral replication over time.

\section{T-Cell Responses}

During the acute stage of pathogenesis in Ifnar $1^{-/-}$mice, there is an influx of leukocytes into the infected liver, forming foci that can be observed in H\&E-stained liver sections. Flow cytometry of isolated liver-derived leukocytes reveals these populations to be a mixture of macrophages, and NK cells, and T cells, with minor percentages of NK-T cells (Fig. 7) (Hirai-Yuki et al. 2016a). Although these subsets are present, it is not evident that they are critical for acute stage pathogenesis, as depletions of T cells and $\mathrm{NK}^{+}$cells showed no effect on ALT or virus burden in the liver. However, during the persistence phase of the infection in mice, there is an expansion of $\mathrm{T}$ cells that is greater at 9 weeks postinfection than at 1 week of infection based on cytokine expression (Hirai-Yuki et al. 2016a). The response in mice is similar to the delayed $\mathrm{T}$-cell response in infected chimpanzees, which emerges around 4 to 5 weeks postinfection (Zhou et al. 2012; see Wedemeyer 2018).

Using overlapping peptide pools derived from the HAV polyprotein, we observed roughly $3 \times 10^{5}$ virus-specific $\mathrm{CD}^{+} \mathrm{T}$ cells that produced IFN- $\gamma$ in response to peptides at 9 weeks postinfection. We do not know at epitope-specific resolution what the $\mathrm{T}$ cells recognize, but it appears that the splenic $\mathrm{CD} 4^{+} \mathrm{T}$-cell response is broadly spread among several viral proteins, including VP1, 2B, 2C, 3A, and $3 \mathrm{C}^{\text {pro }}$. For $\mathrm{CD}^{+} \mathrm{T}$ cells, the overall response was very small, perhaps $8 \times 10^{4}$ cells in total, and appeared more restricted to epitopes derived from VP1, 2B, and $2 \mathrm{C}$. In terms of delayed kinetics, bias toward $\mathrm{CD} 4^{+} \mathrm{T}$ cells, and breadth of the response, the mouse model resembles $\mathrm{T}$-cell responses in the blood of chimpanzees (Zhou et al. 2012). Only limited analyses of the $\mathrm{T}$-cell response in Ifnar $1^{-1-}$ mice have been completed, and there is a need to better quantify and functionally assess $\mathrm{T}$-cell responses within the liver. It will be important to learn whether T-cell activity within the liver limits virus replication or contributes to sustained liver damage over time. Along this line, T-cell expression of cytolytic molecules or apoptosis-inducing cytokines (e.g., TNF, FASL, TRAIL) may be involved in killing infected cells, resulting in ALT release.

Liver immunobiology is complex and distinct from that in lymphoid tissues (Protzer et al. 2012; Crispe 2016; Grakoui and Crispe 2016) and there are layers of regulation that restrict T-cell responses. It is interesting to speculate that liver-tropic viruses use these mechanisms to establish persistence, and the Ifnar $1^{-/-}$ mouse model can be used to explore these processes. It is striking that the T-cell response is small and delayed during the acute phase of infection when HAV is rapidly replicating and increasing in level. The underlying explanation may be related to virus perturbation of antigen presentation, as seen with other picornaviruses (Kemball et al. 2009), or the recruitment of immune-suppressive cells to the liver (see below). Perhaps HAV interference in IFN signaling impairs T-cell responses that greatly rely on direct IFN signaling at certain stages of infection (Kolumam et al. 2005; Aichele et al. 2006; HavenarDaughton et al. 2006; Le Bon et al. 2006; Crouse et al. 2014; Xu et al. 2014). More generally, the HAV model can be used to improve our understanding of how $\mathrm{T}$ cells are typically regulated within the liver. Such information will be instrumental for designing T-cell-based vaccines against liver-tropic viruses.

\section{Monocyte-Derived Suppressor Cells (MDSCs)}

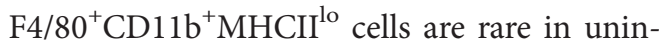
fected mouse livers and spleens but accumulate in HAV-infected Ifnarl ${ }^{-/-}$liver (Fig. 7). Phenotypically, these cells resemble MDSCs that have been observed in other virus infections, such as in $\mathrm{HBV}$, or HCV infections of humans or mice with chimeric livers, and in some tumor environments (Almand et al. 2001; Ochoa et al. 2007; Hoechst et al. 2008, 2009; Tacke et al. 2012; Goh et al. 2013; Pallett et al. 2015; Goh et al. 2016; Shin et al. 2016; Zhai et al. 
A

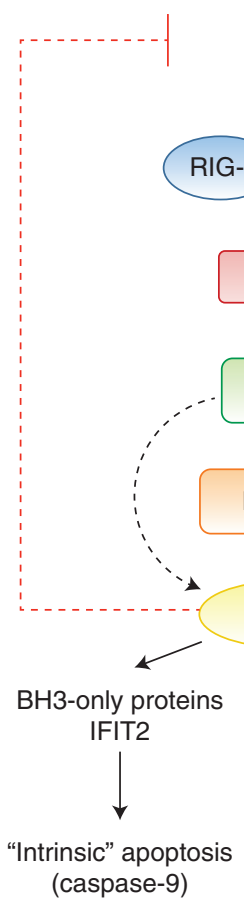

Ifnar ${ }^{1-}$

HAV

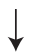

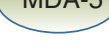

MAVS

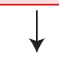

$\mathrm{RF3/7} \rightarrow$ IRF3-Bax $\rightarrow$ "Intrinsic"

(caspase-9)

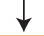

IFN- $\alpha \beta$

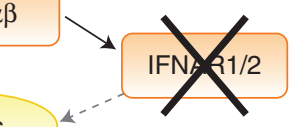

ISGs

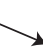

CCL2, CCL5

NK/NKT cells

$\mathrm{T}$ cells

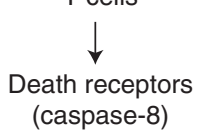

B

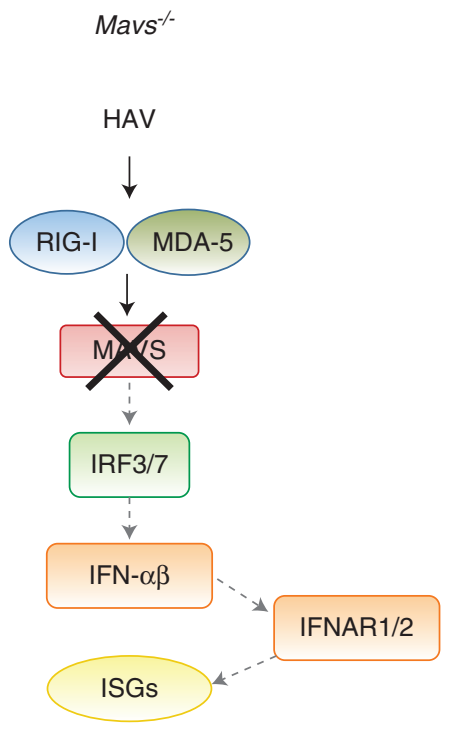

Figure 8. Mitochondrial antiviral-signaling protein (MAVS)- and IRF3/7-dependent signaling limits hepatitis A virus (HAV) replication and triggers hepatocyte apoptosis. (A) HAV infection of hepatocytes in Ifnar $1^{-1-}$ mice results in RIG-I/MDA recognition of cytosolic viral RNA and MAVS activation, leading to phosphorylation and dimerization of IRF3/IRF7 and interferon (IFN) production. Although IFN is inactive because of the absence of type I IFN receptors, activated IRF3 directly stimulates the transcription of proapoptotic IFN-stimulated genes (ISGs), and chemokines such as CCL5, that induce hepatocellular apoptosis and drive inflammation within the liver. Although much less effective than IFN-driven ISG responses in wild-type mice that completely restrict replication, IRF3-stimulated gene expression also suppresses viral replication over time in concert with the induction of adaptive immunity. Activated IRF3 may directly induce apoptosis or may induce the expression of proapoptotic factors that result in hepatocyte apoptosis. (B) In infected $\mathrm{Mavs}^{-1-}$ mice, IRF3 remains inactive, and there is no induction of apoptosis by either mechanism. Nuclear factor (NF)- $\kappa \mathrm{B}$ is unlikely to have a critical role in disease pathogenesis, as it should be activated through MAVS in infected $\operatorname{Irf} 3^{-1-} \operatorname{Irf} 7^{-/-}$mice that (like Mavs $^{-1-}$ mice) show no evidence of disease.

2017). These cells are attracted to CCL2 (Huang et al. 2007), which is induced in HAV-infected livers (Hirai-Yuki et al. 2016a). They express nitric oxide, reactive oxygen species, arginase, or TGF- $\beta$ to suppress $\mathrm{CD}^{+} \mathrm{T}$ cells, NK cells, dendritic cells, and macrophages (Gabrilovich and Nagaraj 2009; Tacke and Zimmermann 2014). It is interesting to speculate that HAV stimulates signaling mechanisms that recruit immune-suppressive cells that limit adaptive immune responses and allow virus persistence.

\section{FUTURE DIRECTIONS}

Although described only recently, murine models of HAV infection of mice have been very informative with regard to understanding HAV restriction, tissue tropism, immune responses, and molecular mechanisms of pathogenesis. There are opportunities to improve these models, but there are conspicuous features of the virus-host interaction that should be further investigated using the existing Ifnar $1^{-/-}$mouse model. For example, far more molecular detail is needed to 
A. Hirai-Yuki et al.

explain how HAV induces pathogenesis, and there are other aspects of HAV biology that need clarification, such as how a prototypical "acute" virus establishes persistence in the mouse. Studies should also characterize virusspecific T cells and their contribution to eventual virus control and liver damage as well as the impact of MDSCs on virus control and liver repair.

\section{Refining Murine Models of HAV Infection}

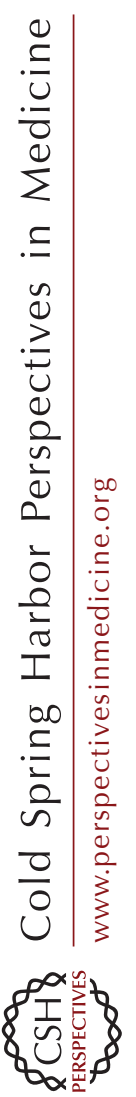

A caveat with the Ifnar $1^{-/-}$mouse model is that all cells lack type I IFN signaling. Although $\mathrm{HAV}$-infected type I IFN receptor-knockout mice can produce anti-HAV antibody and a limited HAV-specific T-cell response, it is well established that type I IFN promotes adaptive immunity. Thus, the adaptive immune response in these mice is likely weakened or modified by the absence of this critical signal into T and B cells. We are undertaking two approaches to improve the model. The first approach is to establish mice with hepatocyte-specific loss of Ifnar1 expression, so that the role of normal antiviral immune responses can be assessed in mice with livers replicating $\mathrm{HAV}$.

A more elegant approach to advance this model is to humanize the mouse liver, for example, by genetically editing mouse Mavs so that mouse MAVS can be cleaved by the HAV 3ABC protease. Such a refinement could lead to a model that very closely resembles events that occur in human infections, and will also determine the importance of MAVS cleavage in HAV pathogenesis. The virus will be challenged to enter hepatocytes, rapidly express 3ABC, and cleave MAVS expressed at normal, physiologic levels. Slight delays in the kinetics of MAVS cleavage may allow for limited signaling, IFN expression, and either restricted replication or alterations in subsequent inflammatory or apoptotic processes. Mice with humanized MAVS may be permissive for HAV replication in hepatocytes in the context of unperturbed HAV-specific adaptive immune responses, or other species-specific restrictions may become evident in the innate immune response, effectively blocking replication, when the virus itself must disrupt a functional MAVS signaling pathway.
Route of Infection and Transmission of HAV to Naïve Mice

In humans, HAV is typically transmitted fecalorally through the ingestion of contaminated food or water. Through unknown mechanisms, HAV overcomes the intestinal barrier and arrives at the liver through the blood. Infection has not been convincingly shown in gastrointestinal tissues of primates, and indeed only very small amounts of viral RNA are found in either the small or large intestine of infected $\mathrm{Mavs}^{-1-}$ mice (Hirai-Yuki et al. 2016a). Whereas intravenous inoculation efficiently establishes infection in the liver of Ifnar $^{-/-}$mice, resulting in viremia and fecal shedding of virus via the biliary system, we were unable to establish infection in mice doubly deficient for expression of both type I and type II IFN receptors (Ifnar $1^{-/-}$Ifngr $1^{-/-}$ mice) by gavage of high titer virus. Similarly, oral gavage of virus did not lead to infection of Alb-uPA/SCID beige mice with chimeric human livers. We do not know what interferes with intestinal infection in mice. One hypothesis is that HAV is restricted by type III IFN (IFN$\lambda$ ) in the gut. IFN- $\lambda$ plays a major role in antivirus defense in the intestinal mucosa, as shown in murine rotavirus, reovirus, and norovirus infections (Pott et al. 2011; Baldridge et al. 2015; Mahlakoiv et al. 2015; Nice et al. 2015), and MAVS induces the expression of IFN- $\lambda$ (Ding and Robek 2014). Thus, IFN- $\lambda$ may restrict HAV replication in the gut, as type I IFN does in the liver. This restriction can be evaluated by comparing oral delivery in mice genetically deficient for both the type I and type III IFN receptors. An alternative hypothesis is that an unknown essential HAV receptor is not expressed on the intestinal epithelial cells of mice. $\mathrm{M}$ cells are involved in moving pathogens across the epithelium by transcytosis (Mabbott et al. 2013) and are required for intestinal replication of murine norovirus and reovirus infection (Gonzalez-Hernandez et al. 2014), but may be unable to transfer HAV across this boundary in mice. The fact that virus infection can be achieved in Alb-uPA/SCID mice by nasal inoculation is surprising, and requires further investigation. 


\section{BOX 1. OUTSTANDING QUESTIONS}

1. What is the principal cellular receptor for HAV in the mouse?

2. What are the downstream mediators of MAVS-IRF3/7-dependent hepatocyte death?

3. How does HAV overcome the intestinal barrier in natural infection to achieve fecal-oral transmission?

4. Does HAV RNA persist in the liver as infectious virus?

5. What role does adaptive immunity play in pathogenesis and eventual control of infection?

\section{CONCLUDING REMARKS}

The recent development of murine models of hepatitis A has revealed the critical importance of innate immune responses in determining host species range and disease pathogenesis. One striking finding is that MAVS-mediated signaling itself initiates intrinsic apoptosis of infected hepatocytes and acute inflammatory responses in the liver. In the presence of MAVS, immune cells are recruited to the site of inflammation and there is enhanced virus clearance and adaptive immunity against the virus. These data provide fresh insight into why HAV, and HCV as well, have evolved viral proteases that degrade MAVS. This mechanism not only provides for escape from IFN-mediated restriction of virus replication, but may also limit pathogenesis and liver injury, thereby facilitating virus persistence and spread. Although much progress has been made, there is still much to be learned about host-virus interactions in HAV infection that can now be interrogated using new murine models. The lessons learned from studying the immunology of the HAV-infected mouse live will likely impact our understanding of other hepatotropic virus infections (see Box 1).

\section{ACKNOWLEDGMENTS}

This work is funded in part by grants from the National Institutes of Health (NIH) (R01AI103083, U19-AI109965 to S.M.L.; R21-AI 117575 to J.K.W.; and R01-A131685 to S.M.L. \& J.K.W.), and National Cancer Institute (NCI) Center Core Support Grant P30-CA016086 to the Lineberger Comprehensive Cancer Center.

\section{REFERENCES}

* Reference is also in this collection.

Aichele P, Unsoeld H, Koschella M, Schweier O, Kalinke U, Vucikuja S. 2006. CD8 T cells specific for lymphocytic choriomeningitis virus require type I IFN receptor for clonal expansion. J Immunol 176: 4525-4529.

Almand B, Clark JI, Nikitina E, van Beynen J, English NR, Knight SC, Carbone DP, Gabrilovich DI. 2001. Increased production of immature myeloid cells in cancer patients: A mechanism of immunosuppression in cancer. J Immunol 166: 678-689.

Altevogt BM, Pankevich DE, Shelton-Davenport MK, Kahn JP, eds. 2011. Chimpanzees in biomedical and behavioral research: Assessing the necessity. The National Academies Press, Washington, DC.

Baldridge MT, Nice TJ, McCune BT, Yokoyama CC, Kambal A, Wheadon M, Diamond MS, Ivanova Y, Artyomov M, Virgin HW. 2015. Commensal microbes and interferon- $\lambda$ determine persistence of enteric murine norovirus infection. Science 347: 266-269.

Besch R, Poeck H, Hohenauer T, Senft D, Hacker G, Berking C, Hornung V, Endres S, Ruzicka T, Rothenfusser S, et al. 2009. Proapoptotic signaling induced by RIG-I and MDA-5 results in type I interferon-independent apoptosis in human melanoma cells. J Clin Invest 119: 23992411.

Bility MT, Nio K, Li F, McGivern DR, Lemon SM, Feeney ER, Chung RT, Su L. 2016. Chronic hepatitis C infection-induced liver fibrogenesis is associated with M2 macrophage activation. Sci Rep 6: 39520.

Billerbeck E, Wolfisberg R, Fahnøe U, Xiao JW, Quirk C, Luna JM, Cullen JM, Hartlage AS, Chiriboga L, Ghoshal K, et al. 2017. Mouse models of acute and chronic hepacivirus infection. Science 357: 204-208.

Brown JJ, Parashar B, Moshage H, Tanaka KE, Engelhardt D, Rabbani E, Roy-Chowdhury N, Roy-Chowdhury J. 2000. A long-term hepatitis B viremia model generated by transplanting nontumorigenic immortalized human hepatocytes in Rag-2-deficient mice. Hepatology 31: 173181.

Chattopadhyay S, Kuzmanovic T, Zhang Y, Wetzel JL, Sen GC. 2016. Ubiquitination of the transcription factor IRF3 activates RIPA, the apoptotic pathway that protects mice from viral pathogenesis. Immunity 44: 1151-1161. 
A. Hirai-Yuki et al.

Chayama K, Hayes CN, Hiraga N, Abe H, Tsuge M, Imamura M. 2011. Animal model for study of human hepatitis viruses. J Gastroenterol Hepatol 26: 13-18.

Cohen JI, Ticehurst JR, Purcell RH, Buckler-White A, Baroudy BM. 1987. Complete nucleotide sequence of wildtype hepatitis A virus: Comparison with different strains of hepatitis A virus and other picornaviruses. J Virol 61: 50-59.

Costafreda MI, Ribes E, Franch A, Bosch A, Pinto RM. 2012. A single mutation in the glycophorin A binding site of hepatitis A virus enhances virus clearance from the blood and results in a lower fitness variant. J Virol 86: 78877895.

Crispe IN. 2016. Hepatocytes as immunological agents. J Immunol 196: 17-21.

Crouse J, Bedenikovic G, Wiesel M, Ibberson M, Xenarios I, Von Laer D, Kalinke U, Vivier E, Jonjic S, Oxenius A. 2014. Type I interferons protect T cells against NK cell attack mediated by the activating receptor NCR1. Immunity 40: 961-973.

* Cullen JM. 2018. Comparative pathology of hepatitis A virus and hepatitis E virus infection. Cold Spring Harb Perspect Med doi: 10.1101/cshperspect.a033456.

Das A, Hirai-Yuki A, Gonzalez-Lopez O, Rhein B, MollerTank S, Brouillette R, Hensley L, Misumi I, Lovell W, Cullen JM, et al. 2017. TIM1 (HAVCR1) is not essential for cellular entry of either quasi-enveloped or naked hepatitis A virions. mBio 8: e00969-17.

Ding S, Robek MD. 2014. Peroxisomal MAVS activates IRF1-mediated IFN- $\lambda$ production. Nat Immunol 15: 700-701.

Doceul V, Bagdassarian E, Demange A, Pavio N. 2016. Zoonotic hepatitis $\mathrm{E}$ virus: Classification, animal reservoirs and transmission routes. Viruses 8: E270.

Dorner M, Horwitz JA, Robbins JB, Barry WT, Feng Q, Mu K, Jones CT, Schoggins JW, Catanese MT, Burton DR, et al. 2011. A genetically humanized mouse model for hepatitis C virus infection. Nature 474: 208-211.

Dorner M, Horwitz JA, Donovan BM, Labitt RN, Budell WC, Friling T, Vogt A, Catanese MT, Satoh T, Kawai T, et al. 2013. Completion of the entire hepatitis $C$ virus life cycle in genetically humanized mice. Nature 501: 237241.

Douglas DN, Kawahara T, Sis B, Bond D, Fischer KP, Tyrrell DL, Lewis JT, Kneteman NM. 2010. Therapeutic efficacy of human hepatocyte transplantation in a SCID/uPA mouse model with inducible liver disease. PLOS ONE 5: e9209.

Drexler JF, Corman VM, Lukashev AN, van den Brand JM, Gmyl AP, Brunink S, Rasche A, Seggewibeta N, Feng H, Leijten LM, et al. 2015. Evolutionary origins of hepatitis A virus in small mammals. Proc Natl Acad Sci 112: 1519015195.

Feigelstock D, Thompson P, Mattoo P, Zhang Y, Kaplan GG. 1998. The human homolog of HAV cr-1 codes for a hepatitis A virus cellular receptor. J Virol 72: 6621-6628.

Feigelstock DA, Thompson P, Kaplan GG. 2005. Growth of hepatitis A virus in a mouse liver cell line. J Virol 79: 2950-2955.
* Feng Z, Lemon SM. 2018. Innate immunity to enteric hepatitis viruses. Cold Spring Harb Perspect Med doi: 10.1101/ cshperspect.a033464.

Feng Z, Hensley L, McKnight KL, Hu F, Madden V, Ping L, Jeong SH, Walker C, Lanford RE, Lemon SM. 2013. A pathogenic picornavirus acquires an envelope by hijacking cellular membranes. Nature 496: 367-371.

Feng Z, Li Y, McKnight KL, Hensley L, Lanford RE, Walker CM, Lemon SM. 2015. Human pDCs preferentially sense enveloped hepatitis A virions. J Clin Invest 125: 169-176.

Foster JR, Lund G, Sapelnikova S, Tyrrell DL, Kneteman NM. 2014. Chimeric rodents with humanized liver: Bridging the preclinical/clinical trial gap in ADME/toxicity studies. Xenobiotica 44: 109-122.

Gabrilovich DI, Nagaraj S. 2009. Myeloid-derived suppressor cells as regulators of the immune system. Nat Rev Immunol 9: 162-174.

Garcia-Sastre A, Biron CA. 2006. Type 1 interferons and the virus-host relationship: A lesson in detente. Science 312: 879-882.

Glikson M, Galun E, Oren R, Tur-Kaspa R, Shouval D. 1992. Relapsing hepatitis A. Review of 14 cases and literature survey. Medicine 71: 14-23.

Goh C, Narayanan S, Hahn YS. 2013. Myeloid-derived suppressor cells: The dark knight or the joker in viral infections? Immunol Rev 255: 210-221.

Goh CC, Roggerson KM, Lee HC, Golden-Mason L, Rosen HR, Hahn YS. 2016. Hepatitis C virus-induced myeloidderived suppressor cells suppress NK cell IFN- $\gamma$ production by altering cellular metabolism via arginase-1. J Immunol 196: 2283-2292.

Gonzalez-Hernandez MB, Liu T, Payne HC, Stencel-Baerenwald JE, Ikizler M, Yagita H, Dermody TS, Williams IR, Wobus CE. 2014. Efficient norovirus and reovirus replication in the mouse intestine requires microfold (M) cells. J Virol 88: 6934-6943.

Grakoui A, Crispe IN. 2016. Presentation of hepatocellular antigens. Cell Mol Immunol 13: 293-300.

Grandvaux N, Servant MJ, tenOever B, Sen GC, Balachandran S, Barber GN, Lin R, Hiscott J. 2002. Transcriptional profiling of interferon regulatory factor 3 target genes: Direct involvement in the regulation of interferon-stimulated genes. J Virol 76: 5532-5539.

Guidotti LG, Matzke B, Schaller H, Chisari FV. 1995. Highlevel hepatitis B virus replication in transgenic mice. $J$ Virol 69: 6158-6169.

Gust ID, Lehmann NI, Crowe S, McCrorie M, Locarnini SA, Lucas CR. 1985. The origin of the HM175 strain of hepatitis A virus. J Infect Dis 151: 365-367.

Havenar-Daughton C, Kolumam GA, Murali-Krishna K. 2006. Cutting edge: The direct action of type I IFN on CD4 T cells is critical for sustaining clonal expansion in response to a viral but not a bacterial infection. J Immunol 176: 3315-3319.

Heckel JL, Sandgren EP, Degen JL, Palmiter RD, Brinster RL. 1990. Neonatal bleeding in transgenic mice expressing urokinase-type plasminogen activator. Cell 62: 447-456.

Hirai-Yuki A, Hensley L, McGivern DR, Gonzalez-Lopez O, Das A, Feng H, Sun L, Wilson JE, Hu F, Feng Z, et al. 2016a. MAVS-dependent host species range and patho- 
genicity of human hepatitis A virus. Science 353 : 15411545.

Hirai-Yuki A, Hensley L, Whitmire JK, Lemon SM. 2016 b. Biliary secretion of quasi-enveloped human hepatitis A virus. $m$ Bio 7: $\mathrm{e} 01998$.

Hoechst B, Ormandy LA, Ballmaier M, Lehner F, Kruger C, Manns MP, Greten TF, Korangy F. 2008. A new population of myeloid-derived suppressor cells in hepatocellular carcinoma patients induces $\mathrm{CD} 4^{+} \mathrm{CD} 25^{+} \mathrm{Foxp}^{+} \mathrm{T}$ cells. Gastroenterology 135: 234-243.

Hoechst B, Voigtlaender T, Ormandy L, Gamrekelashvili J, Zhao F, Wedemeyer H, Lehner F, Manns MP, Greten TF, Korangy F. 2009. Myeloid derived suppressor cells inhibit natural killer cells in patients with hepatocellular carcinoma via the NKp30 receptor. Hepatology 50: 799-807.

Hornei B, Kammerer R, Moubayed P, Frings W, Gauss-Muller V, Dotzauer A. 2001. Experimental hepatitis A virus infection in guinea pigs. J Med Virol 64: 402-409.

Huang B, Lei Z, Zhao J, Gong W, Liu J, Chen Z, Liu Y, Li D, Yuan Y, Zhang GM, et al. 2007. CCL2/CCR2 pathway mediates recruitment of myeloid suppressor cells to cancers. Cancer Lett 252: 86-92.

Joyce MA, Walters KA, Lamb SE, Yeh MM, Zhu LF, Kneteman N, Doyle JS, Katze MG, Tyrrell DL. 2009. HCV induces oxidative and ER stress, and sensitizes infected cells to apoptosis in SCID/Alb-uPA mice. PLoS Pathog 5: e1000291.

Kemball CC, Harkins S, Whitmire JK, Flynn CT, Feuer R, Whitton JL. 2009. Coxsackievirus B3 inhibits antigen presentation in vivo, exerting a profound and selective effect on the MHC class I pathway. PLoS Pathog 5: e1000618.

Kolumam GA, Thomas S, Thompson LJ, Sprent J, MuraliKrishna K. 2005. Type I interferons act directly on CD8 T cells to allow clonal expansion and memory formation in response to viral infection. J Exp Med 202: 637-650.

Lanford RE, Feng Z, Chavez D, Guerra B, Brasky KM, Zhou Y, Yamane D, Perelson AS, Walker CM, Lemon SM. 2011. Acute hepatitis A virus infection is associated with a limited type I interferon response and persistence of intrahepatic viral RNA. Proc Natl Acad Sci 108: 11223-11228.

* Lanford RE, Walker CM, Lemon SM. 2018. Nonhuman primate models of hepatitis A virus and hepatitis E virus infection. Cold Spring Harb Perspect Med doi: 10.1101/ cshperspect.a031815.

Le Bon A, Durand V, Kamphuis E, Thompson C, BulfonePaus S, Rossmann C, Kalinke U, Tough DF. 2006. Direct stimulation of $\mathrm{T}$ cells by type I IFN enhances the $\mathrm{CD} 8^{+} \mathrm{T}$ cell response during cross-priming. J Immunol 176: 4682-4689.

Lemon SM. 1985. Type A viral hepatitis. New developments in an old disease. N Engl J Med 313: 1059-1067.

Li F. 2013. Receptor recognition and cross-species infections of SARS coronavirus. Antiviral Res 100: 246-254.

* Li TC, Wakita F. 2018. Small animal models of hepatitis E viruses. Cold Spring Harb Perspect Med doi: 10.1101/ cshperspect.a032581.

Mabbott NA, Donaldson DS, Ohno H, Williams IR, Mahajan A. 2013. Microfold (M) cells: Important immunosurveillance posts in the intestinal epithelium. Mucosal Immunol 6: 666-677.
Mahlakoiv T, Hernandez P, Gronke K, Diefenbach A, Staeheli P. 2015. Leukocyte-derived IFN- $\alpha / \beta$ and epithelial IFN- $\lambda$ constitute a compartmentalized mucosal defense system that restricts enteric virus infections. PLoS Pathog 11: e1004782.

Manangeeswaran M, Jacques J, Tami C, Konduru K, Amharref N, Perrella O, Casasnovas JM, Umetsu DT, Dekruyff RH, Freeman GJ, et al. 2012. Binding of hepatitis A virus to its cellular receptor 1 inhibits T-regulatory cell functions in humans. Gastroenterology 142: 1516-1525. e1513.

McIntire JJ, Umetsu SE, Macaubas C, Hoyte EG, Cinnioglu C, Cavalli-Sforza LL, Barsh GS, Hallmayer JF, Underhill PA, Risch NJ, et al. 2003. Immunology: Hepatitis A virus link to atopic disease. Nature 425: 576.

McKnight KL, Xie L, Gonzalez-Lopez O, Rivera-Serrano EE, Chen X, Lemon SM. 2017. Protein composition of the hepatitis A virus quasi-envelope. Proc Natl Acad Sci 114: 6587-6592.

Mercer DF, Schiller DE, Elliott JF, Douglas DN, Hao C, Rinfret A, Addison WR, Fischer KP, Churchill TA, Lakey JR, et al. 2001. Hepatitis C virus replication in mice with chimeric human livers. Nat Med 7: 927-933.

Meuleman P, Leroux-Roels G. 2008. The human liver-uPASCID mouse: A model for the evaluation of antiviral compounds against HBV and HCV. Antiviral Res 80: 231238.

Moller-Tank S, Maury W. 2014. Phosphatidylserine receptors: Enhancers of enveloped virus entry and infection. Virology 468-470: 565-580.

Nice TJ, Baldridge MT, McCune BT, Norman JM, Lazear HM, Artyomov M, Diamond MS, Virgin HW. 2015. Interferon-lambda cures persistent murine norovirus infection in the absence of adaptive immunity. Science 347 : 269-273.

Ochoa AC, Zea AH, Hernandez C, Rodriguez PC. 2007. Arginase, prostaglandins, and myeloid-derived suppressor cells in renal cell carcinoma. Clin Cancer Res 13: 721s726s.

Pallett LJ, Gill US, Quaglia A, Sinclair LV, Jover-Cobos M, Schurich A, Singh KP, Thomas N, Das A, Chen A, et al. 2015. Metabolic regulation of hepatitis B immunopathology by myeloid-derived suppressor cells. Nat Med 21: 591-600.

Pang D. 2013. "To HAV or not to HAV: Novel hepatitis A virus (HAV) infection in a chimeric mouse model." $\mathrm{PhD}$ thesis, University of Alberta, Edmonton, Canada.

Petrasek J, Iracheta-Vellve A, Csak T, Satishchandran A, Kodys K, Kurt-Jones EA, Fitzgerald KA, Szabo G. 2013. STING-IRF3 pathway links endoplasmic reticulum stress with hepatocyte apoptosis in early alcoholic liver disease. Proc Natl Acad Sci 110: 16544-16549.

Pott J, Mahlakoiv T, Mordstein M, Duerr CU, Michiels T, Stockinger S, Staeheli P, Hornef MW. 2011. IFN- $\lambda$ determines the intestinal epithelial antiviral host defense. Proc Natl Acad Sci 108: 7944-7949.

Protzer U, Maini MK, Knolle PA. 2012. Living in the liver: Hepatic infections. Nat Rev Immunol 12: 201-213.

Qu L, Feng Z, Yamane D, Liang Y, Lanford RE, Li K, Lemon SM. 2011. Disruption of TLR3 signaling due to cleavage of TRIF by the hepatitis A virus protease-polymerase processing intermediate, 3CD. PLoS Pathog 7: e1002169. 
A. Hirai-Yuki et al.

Reich NC. 2013. A death-promoting role for ISG54/IFIT2. J Interferon Cytokine Res 33: 199-205.

Ren RB, Costantini F, Gorgacz EJ, Lee JJ, Racaniello VR. 1990. Transgenic mice expressing a human poliovirus receptor: A new model for poliomyelitis. Cell 63: 353362.

* Sander AL, Corman VM, Lukashev AN, Drexler JF. 2018 Evolutionary origins of enteric hepatitis viruses. Cold Spring Harb Perspect Med doi: 10.1101/cshperspect. a031690.

Sandgren EP, Palmiter RD, Heckel JL, Daugherty CC, Brinster RL, Degen JL. 1991. Complete hepatic regeneration after somatic deletion of an albumin-plasminogen activator transgene. Cell 66: 245-256.

Sang X, Wang A, Ding J, Kong H, Gao X, Li L, Chai T, Li Y, Zhang K, Wang C, et al. 2015. Adaptation of H9N2 AIV in guinea pigs enables efficient transmission by direct contact and inefficient transmission by respiratory droplets. Sci Rep 5: 15928.

Shin EC, Sung PS, Park SH. 2016. Immune responses and immunopathology in acute and chronic viral hepatitis. Nat Rev Immunol 16: 509-523.

Sjogren MH, Tanno H, Fay O, Sileoni S, Cohen BD, Burke DS, Feighny RJ. 1987. Hepatitis A virus in stool during clinical relapse. Ann Intern Med 106: 221-226.

Suarez-Amaran L, Usai C, Di Scala M, Godoy C, Ni Y, Hommel M, Palomo L, Segura V, Olague C, Vales A, et al. 2017. A new HDV mouse model identifies mitochondrial antiviral signaling protein (MAVS) as a key player in IFN- $\beta$ induction. J Hepatol 67: 669-679.

Tacke F, Zimmermann HW. 2014. Macrophage heterogeneity in liver injury and fibrosis. J Hepatol 60: 1090-1096.

Tacke RS, Lee HC, Goh C, Courtney J, Polyak SJ, Rosen HR, Hahn YS. 2012. Myeloid suppressor cells induced by hepatitis $C$ virus suppress $T$-cell responses through the production of reactive oxygen species. Hepatology 55: 343353.

Vallbracht A, Hofmann L, Wurster KG, Flehmig B. 1984. Persistent infection of human fibroblasts by hepatitis A virus. J Gen Virol 65: 609-615.
Vallbracht A, Gabriel P, Zahn J, Flehmig B. 1985. Hepatitis A virus infection and the interferon system. J Infect Dis 152: 211-213.

Walters KA, Joyce MA, Thompson JC, Smith MW, Yeh MM, Proll S, Zhu LF, Gao TJ, Kneteman NM, Tyrrell DL, et al. 2006. Host-specific response to HCV infection in the chimeric SCID-beige/Alb-uPA mouse model: Role of the innate antiviral immune response. PLoS Pathog 2: e59.

Wang D, Fang L, Wei D, Zhang H, Luo R, Chen H, Li K, Xiao S. 2014. Hepatitis A virus $3 \mathrm{C}$ protease cleaves NEMO to impair induction of $\beta$ interferon. J Virol 88: 1025210258.

Washburn ML, Bility MT, Zhang L, Kovalev GI, Buntzman A, Frelinger JA, Barry W, Ploss A, Rice CM, Su L. 2011. A humanized mouse model to study hepatitis $\mathrm{C}$ virus infection, immune response, and liver disease. Gastroenterology 140: 1334-1344.

* Wedemeyer H. 2018. Adaptive immunity to enteric hepatitis viruses. Cold Spring Harb Perspect Med doi: 10.1101/ cshperspect.a033472.

Winer BY, Ding Q, Gaska JM, Ploss A. 2016. In vivo models of hepatitis B and C virus infection. FEBS Lett 590: 19871999.

Xu HC, Grusdat M, Pandyra AA, Polz R, Huang J, Sharma P, Deenen R, Kohrer K, Rahbar R, Diefenbach A, et al. 2014. Type I interferon protects antiviral CD8 ${ }^{+} \mathrm{T}$ cells from NK cell cytotoxicity. Immunity 40: 949-960.

Yang Y, Liang Y, Qu L, Chen Z, Yi M, Li K, Lemon SM. 2007. Disruption of innate immunity due to mitochondrial targeting of a picornaviral protease precursor. Proc Natl Acad Sci 104: 7253-7258.

Zhai N, Li H, Song H, Yang Y, Cui A, Li T, Niu J, Crispe IN, Su L, Tu Z. 2017. Hepatitis C virus induces MDSCs-like monocytes through TLR2/PI3K/AKT/STAT3 signaling. PLoS ONE 12: e0170516.

Zhou Y, Callendret B, Xu D, Brasky KM, Feng Z, Hensley LL, Guedj J, Perelson AS, Lemon SM, Lanford RE, et al. 2012. Dominance of the $\mathrm{CD}^{+}{ }^{+} \mathrm{T}$ helper cell response during acute resolving hepatitis A virus infection. J Exp Med 209: 1481-1492. 


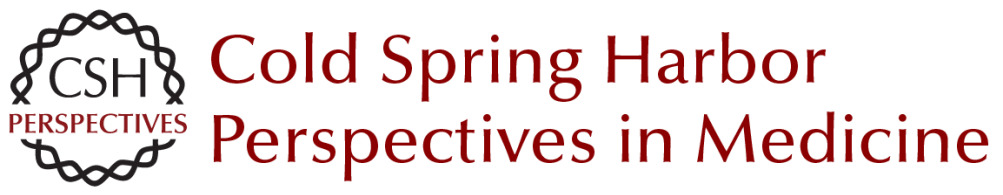

\section{Murine Models of Hepatitis A Virus Infection}

Asuka Hirai-Yuki, Jason K. Whitmire, Michael Joyce, D. Lorne Tyrrell and Stanley M. Lemon

Cold Spring Harb Perspect Med 2019; doi: 10.1101/cshperspect.a031674 originally published online April 16, 2018

\section{Subject Collection Enteric Hepatitis Viruses}

Hepatitis A Virus Genome Organization and Replication Strategy

Kevin L. McKnight and Stanley M. Lemon

Adaptive Immune Responses in Hepatitis A Virus and Hepatitis E Virus Infections

Christopher M. Walker

Small Animal Models of Hepatitis E Virus Infection Tian-Cheng Li and Takaji Wakita

Acute and Persistent Hepatitis E Virus Genotype 3 and 4 Infection: Clinical Features, Pathogenesis, and Treatment Nassim Kamar and Sven Pischke

Epidemiology of Genotype 1 and 2 Hepatitis E Virus Infections

Kenrad E. Nelson, Alain B. Labrique and Brittany L. Kmush

History of the Discovery of Hepatitis A Virus Stephen M. Feinstone

Epidemiology and Transmission of Hepatitis A Virus and Hepatitis E Virus Infections in the United States

Megan G. Hofmeister, Monique A. Foster and Eyasu H. Teshale

Stem Cell-Derived Culture Models of Hepatitis E Virus Infection

Viet Loan Dao Thi, Xianfang Wu and Charles $M$. Rice
Evolutionary Origins of Enteric Hepatitis Viruses Anna-Lena Sander, Victor Max Corman, Alexander N. Lukashev, et al.

Enterically Transmitted Non-A, Non-B Hepatitis and the Discovery of Hepatitis E Virus

Stanley M. Lemon and Christopher M. Walker

Natural History, Clinical Manifestations, and

Pathogenesis of Hepatitis E Virus Genotype 1 and

2 Infections

Rakesh Aggarwal and Amit Goel

Hepatitis A Virus and Hepatitis E Virus: Emerging and Re-Emerging Enterically Transmitted

Hepatitis Viruses

Stanley M. Lemon and Christopher M. Walker

Hepatitis A Virus Capsid Structure

David I. Stuart, Jingshan Ren, Xiangxi Wang, et al.

Comparative Pathology of Hepatitis A Virus and Hepatitis E Virus Infection John M. Cullen and Stanley M. Lemon

Innate Immunity to Enteric Hepatitis Viruses Zongdi Feng and Stanley M. Lemon

Nonhuman Primate Models of Hepatitis A Virus and Hepatitis E Virus Infections

Robert E. Lanford, Christopher M. Walker and

Stanley M. Lemon

For additional articles in this collection, see http://perspectivesinmedicine.cshlp.org/cgi/collection/ 